\title{
Motor Stimulant Effects of Ethanol Injected into the Substantia Nigra Pars Reticulata: Importance of Catalase-Mediated Metabolism and the Role of Acetaldehyde
}

\author{
Maria N Arizzi-LaFrance', Mercè Correa ${ }^{1,2}$, Carlos MG Aragon ${ }^{2}$ and John D Salamone, ${ }^{*, 1}$ \\ 'Department of Psychology, University of Connecticut, Storrs, CT, USA; ${ }^{2}$ Area de Psicobiologia, Universitat Jaume I, Castelló, Spain
}

\begin{abstract}
A series of experiments was conducted to investigate the locomotor effects of local injections of ethanol and the ethanol metabolite, acetaldehyde, into substantia nigra pars reticulata (SNr). Infusions of ethanol into SNr resulted in a dose-related increase in locomotor activity, with maximal effects at a dose of $1.4 \mu \mathrm{mol}$. Ethanol injected into a control site dorsal to substantia nigra failed to stimulate locomotion, and another inactive site was identified in brainstem areas posterior to substantia nigra. The locomotor effects of intranigral ethanol $(1.4 \mu \mathrm{mol})$ were reduced by coadministration of $10 \mathrm{mg} / \mathrm{kg}$ sodium azide, a catalase inhibitor that acts to reduce the metabolism of ethanol into acetaldehyde in the brain. SNr infusions of acetaldehyde, which is the first metabolite of ethanol, also increased locomotion. Taken together, these results indicate that $\mathrm{SNr}$ is one of the sites at which ethanol and acetaldehyde may be acting to induce locomotor activity. These results are consistent with the hypothesis that acetaldehyde is a centrally active metabolite of ethanol, and provide further support for the idea that catalase activity is a critical step in the regulation of ethanol-induced motor activity. These studies have implications for understanding the brain mechanisms involved in mediating the ascending limb of the biphasic dose-response curve for the effect of ethanol on locomotor activity.

Neuropsychopharmacology (2006) 3 I, 997-1008. doi: I0.1038/sj.npp. I300849; published online 17 August 2005
\end{abstract}

Keywords: alcohol; activation; locomotion; basal ganglia

\section{INTRODUCTION}

Ethanol is a sedative-hypnotic drug that has motor stimulant effects at low to moderate doses, and sedative or ataxic effects at higher doses (Read et al, 1960; Pohorecky, 1977; Crabbe et al, 1982; Dudek and Phillips, 1990; Little, 2000; Phillips et al, 2002). Previous studies from our laboratory have demonstrated that central (ie, intraventricular) administration of low doses of ethanol in rats produce behavioral stimulant effects (Arizzi et al, 2003; Correa et al, 2003a,b). The neurochemistry and neuroanatomy of this effect are still unknown, but in view of research demonstrating that GABA is involved in some of the neurochemical and physiological effects of ethanol (Mereu and Gessa, 1985; Marrosu et al, 1989; Grobin et al, 1998; Criswell et al, 1993; Grant and Lovinger, 1995), brain areas at which GABA mechanisms modulate motor activity offer potential substrates for the motor actions of ethanol. One of the brain areas at which GABA mechanisms exert a

\footnotetext{
*Correspondence: Dr JD Salamone, Department of Psychology, University of Connecticut, 406 Babbidge Rd. U-1020, Storrs, CT 06269-1020, USA, Tel: + I 860486 4302, Fax: + I 860486 2760,

E-mail: salamone@psych.psy.uconn.edu

Received 22 April 2005; revised 6 June 2005; accepted 13 June 2005 Online publication: 21 June 2005 at http://www.acnp.org/citations/ Npp062305050266/default.pdf
}

powerful control over locomotion is the substantia nigra pars reticulata $(\mathrm{SNr}) . \mathrm{SNr}$ is a part of the basal ganglia circuitry that has been implicated in several types of motor activity, including muscle rigidity (Crocker, 1997), lever pressing (Trevitt et al, 2001; Correa et al, 2003c), tremor (Finn et al, 1997; Mayorga et al, 1999; Carlson et al, 2003a,b), catalepsy (Scheel-Kruger et al, 1977), circling (Scheel-Kruger et al, 1977), and locomotion (Scheel-Kruger et al, 1977, 1981; Abraini et al, 1999; Trevitt et al, 2002). Although the SNr was once viewed as a region that simply provided feedback regulation of dopamine neurons in the substantia nigra pars compacta, it has become evident in the last few years that the $\mathrm{SNr}$ is one of the two major output nuclei for the basal ganglia (Scheel-Kruger et al, 1981; Young and Penney, 1993; Bevan et al, 1996; Wichmann et al, 1999). SNr is a brain site at which several neurotransmitter systems interact to regulate motor activity. Interactions between dopamine $\mathrm{D} 1$ and $\mathrm{GABA}_{\mathrm{A}}$ receptors in $\mathrm{SNr}$ regulate various aspects of motor activity (Mayorga et al, 1999; Trevitt et al, 2002). GABAergic manipulation of the $\mathrm{SNr}$ produced profound effects on various aspects of motor activity (Scheel-Kruger et al, 1977, 1981). Moreover, SNr is a brain area at which $\mathrm{GABA}_{\mathrm{A}}$ agonists and antagonists exert very potent effects on locomotion (Trevitt et al, 2002). Drugs that act on $\mathrm{GABA}_{\mathrm{A}}$ receptors are very potent at modifying motor output when injected locally into $\mathrm{SNr}$, 
with effects at doses as low as $6 \mathrm{ng}$ for the $\mathrm{GABA}_{\mathrm{A}}$ agonist muscimol (Finn et al, 1997; Trevitt et al, 2002), and 12$18 \mathrm{ng}$ for the $\mathrm{GABA}_{\mathrm{A}}$ antagonist bicuculline (Mayorga et al, 1999; Trevitt et al, 2002; Correa et al, 2003c).

Ethanol has several effects on the physiology and neurochemistry of SNr neurons. Peripherally administered ethanol was shown to inhibit the firing of neurons in the SNr through a GABAergic mechanism (Mereu and Gessa, 1985; Diana et al, 1993). Increased biochemical measures of GABA activity have been reported to occur in $\mathrm{SNr}$ after acute administration of ethanol, and decreased activity was observed after chronic ethanol exposure (Gonzalez and Czachura, 1989). Ethanol enhances GABA function within specific regions of the brain, including $\mathrm{SNr}$, by affecting a $\mathrm{GABA}_{\mathrm{A}}$ receptor with specific structural components (Criswell et al, 1993). Ethanol in the SNr facilitates chloride channel opening, at least in part, through an interaction with the GABA-benzodiazepine receptor-gated chloride ionophore (Marrosu et al, 1989). In view of the findings indicating that $\mathrm{SNr}$ is a brain site that is involved in the regulation of locomotion, and that ethanol exerts modulatory effects over the physiology of $\mathrm{SNr}$ neurons, it is reasonable to investigate the possibility that local injections of ethanol into SNr will affect motor activity.

Another important question in this area is the role of ethanol metabolism in the motor effects of ethanol. Acetaldehyde is an active metabolite that contributes to several of the effects of ethanol (Myers and Veale, 1969; Amir et al, 1980; Hunt, 1996; Smith et al, 1997; Zimatkin and Deitrich, 1997; Quertemont and Tambour, 2004; Quertemont et al, 2005a). Acetaldehyde generally is more potent than ethanol when administered peripherally, both in terms of its behavioral (Quertemont et al, 2005b) and physiological (Foddai et al, 2004) effects. Peripherally administered acetaldehyde has been shown to decrease motor activity under several conditions (Correa et al, 2005). In contrast, acetaldehyde administered into the lateral ventricles was shown to increase locomotor activity (Correa et al, 2003b), and to increase lever pressing rate on a differential reinforcement of low rates $30 \mathrm{~s}$ schedule (DRL30), which is an operant paradigm that generates low rates of responding and therefore is sensitive to the stimulant or disinhibiting effects of drugs (Arizzi et al, 2003). Thus, it has been hypothesized that central acetaldehyde can be partially responsible for the motoractivating effects of ethanol.

The enzyme catalase is thought to be the major complex responsible for the conversion of ethanol to acetaldehyde in the brain, and considerable evidence indicates that brain catalase is involved in the modulation of ethanol-induced motor activity. Mice lacking catalase have lower levels of ethanol-induced locomotion than control animals (Aragon et al, 1992a; Aragon and Amit, 1993), and across several pharmacological manipulations there is a high positive correlation between ethanol-induced locomotor activity and brain catalase activity (Correa et al, 1999a, b, 2000, 2001, 2004a, b; Sanchis-Segura et al, 1999a-c; Pastor et al, 2002). Because catalase has been strongly implicated in ethanol metabolism in the brain (Aragon et al, 1991, 1992b; Gill et al, 1992), it is reasonable to suggest that this enzyme may regulate the motor effects of ethanol through a mechanism tied to the rate of cerebral acetaldehyde production
(Aragon et al, 1989, 1991, 1992b). Previous research indicates that substantia nigra is one of the brain areas with the highest concentration of the ethanol-metabolizing enzyme catalase (McKenna et al, 1976; Brannan et al, 1981; Moreno et al, 1995; Zimatkin and Lindros, 1996), which suggests that SNr may be an important brain locus at which acetaldehyde would modulate locomotor activity.

For these reasons, the present experiments focused upon $\mathrm{SNr}$ as a possible substrate for the locomotor effects of ethanol, and the possible importance of ethanol metabolism in these effects. The first experiment studied the locomotor effects of direct local infusions of ethanol into SNr. The second experiment studied the effects of ethanol infused into control sites dorsal and posterior to the SNr. In view of the possible role of brain ethanol metabolism in mediating the locomotor effects of ethanol, the third experiment studied the effects of the catalase inhibitor, sodium azide, on the locomotor activity induced by $\mathrm{SNr}$ injections of ethanol. The fourth experiment studied the locomotor effects of acetaldehyde infused directly into SNr.

\section{MATERIALS AND METHODS}

\section{Animals}

A total of 177 male Sprague-Dawley rats (Harlan SpragueDawley, Indianapolis, IN) were used in these experiments ( $n=63$ for the ethanol dose-response study, $n=26$ for the dorsal control site study, $n=10$ for the posterior control site study, $n=37$ for the ethanol-sodium azide study, and $n=41$ for the acetaldehyde study). Rats were housed in a colony maintained at $23^{\circ} \mathrm{C}$ with a $12 \mathrm{~L}: 12 \mathrm{D}$ cycle (lights on at 0800). All rats weighed between 280 and $320 \mathrm{~g}$ at the beginning of the study. Water and food were available ad lib in the home cages. Animal protocols were approved by the institutional animal care and use committee, and the methods were in accordance with the Guide for the Care and Use of Laboratory Animals, National Research Council, National Academy Press (1996).

\section{Drugs and Selection of Doses}

For surgery, xylazine and ketamine were purchased from Phoenix Pharmaceutical Inc. (St Joseph, MO). Ethanol (99.5\%, USP grade, Pharmco Products) and acetaldehyde (Fisher Scientific) were dissolved in artificial cerebrospinal fluid (aCSF: $147.2 \mathrm{mM} \mathrm{NaCl}, 1.2 \mathrm{mM} \mathrm{CaCl}_{2}$, and $4.0 \mathrm{mM}$ $\mathrm{KCl})$ to make up the final drug solutions, and aCSF also was the vehicle solution used for control treatments. All drug doses listed reflect the total amount of drug injected bilaterally (ie, both sides added together). Based on previous studies with intraventricular administration (Correa et al, 2003a,b), ethanol was injected in doses in the range of $0.175,0.35,0.7,1.4$, or $2.8 \mu \mathrm{mol}$ (ethanol: 8.05 , $16.1,32.2,64.4$, or $128.8 \mu \mathrm{g}$ ). A previous paper from our laboratory reported that brain extract levels of ethanol following intraventricular infusion of $2.8 \mu \mathrm{mol}$ were 9.6$23.7 \mathrm{mg} / 100 \mathrm{ml}$ (Correa et al, 2003a, p 370), which were lower than reported values of peak brain ethanol concentrations obtained from AA and Wistar rats that selfadministered ethanol (means approximately $65-71 \mathrm{mg}$ / $100 \mathrm{ml}$; Nurmi et al, 1999). Based upon the results of the 
experiment involving ethanol injected into $\mathrm{SNr}$, and previous studies showing that acetaldehyde and ethanol acted on locomotion and operant responding over a similar dose range following intraventricular injections (Correa et al, 2003a, b; Arizzi et al, 2003), acetaldehyde was injected in a dose range of $0.35,0.7,1.4$, or $2.8 \mu \mathrm{mol}$ (acetaldehyde: $15.41,30.83,61.67$, or $123.34 \mu \mathrm{g}$ ). In experiment 3 , sodium azide (Fisher Scientific) was dissolved in physiological saline for intraperitoneal (i.p.) injections. At $30 \mathrm{~min}$ prior to testing, i.p. injections of sodium azide $(0$ or $10 \mathrm{mg} / \mathrm{kg}$ ) were given. The dose and time interval were selected based upon the literature (Sanchis-Segura et al, 1999a), and after pilot studies across a range of doses were used to determine doses that would maximize the effects on catalase inhibition, and minimize any effects the drug would have on locomotion when administered alone.

\section{Surgical Procedure}

Rats were anesthetized with a solution $(1.0 \mathrm{ml} / \mathrm{kg}$, i.p.) that contained ketamine $(100 \mathrm{mg} / \mathrm{ml})$ and xylazine $(20 \mathrm{mg} / \mathrm{ml})$. Bilateral guide cannulae (23 ga stainless steel tubing, Small Parts) were chronically implanted to be $1.0 \mathrm{~mm}$ dorsal to the target structure. The coordinates for the different placements were obtained from Pellegrino and Cushman's (1967) sterotaxic atlas: SNr: AP $-3.0 \mathrm{~mm}$ (from bregma), $\mathrm{ML}+1.9 \mathrm{~mm}$ lateral (from midline), and $\mathrm{DV}-7.8 \mathrm{~mm}$ ventral (from the surface of the skull); dorsal control: AP $-3.0 \mathrm{~mm}$ (from bregma), $\mathrm{ML}+1.9 \mathrm{~mm}$ lateral (from midline), and DV $-5.2 \mathrm{~mm}$ ventral (from the surface of the skull); posterior brainstem control: AP $-3.8 \mathrm{~mm}$ (from bregma), $\mathrm{ML}+1.0 \mathrm{~mm}$ lateral (from midline), and $\mathrm{DV}$ $-8.0 \mathrm{~mm}$ ventral (from the surface of the skull). The incisor bar on the stereotax was set to $5.0 \mathrm{~mm}$ above the interaural line. All animals were single-housed following surgery, and were allowed to recover for 10 days before behavioral testing. Stainless steel stylets were kept in the guide cannulae to maintain their integrity.

\section{Intracranial Drug Injection Procedures}

Intracranial drug injections were made via 30 ga stainless steel injectors extending $1.0 \mathrm{~mm}$ below the tip of the guide cannulae. The injectors were attached to $10.0 \mu \mathrm{l}$ Hamilton syringes by PE-10 tubing. A syringe pump (Harvard Apparatus) drove the injections at a rate of $0.5 \mu \mathrm{l} / \mathrm{min}$ for a total volume of $0.5 \mu \mathrm{l}$ per side. Following the infusion, the injectors remained in place for $1 \mathrm{~min}$ to allow for diffusion of the drug, after which the injectors were removed, stylets were replaced, and animals were immediately placed into the activity chamber for testing.

\section{Behavioral Procedures}

Rats were tested for locomotor activity in an automated Plexiglas stabilimeter chamber $(28 \mathrm{~cm} \times 28 \mathrm{~cm} \times 28 \mathrm{~cm})$ inside a sound-attenuating box. The floor of the chamber consisted of two moveable wire mesh panels $(27 \mathrm{~cm} \times 13 \mathrm{~cm})$ mounted $6.0 \mathrm{~cm}$ above the box floor on a centered rod attached at either end to the sides of the chamber, allowing for slight vertical movement of the floor panels. Movement of the panels was detected by micro- switches mounted outside the chamber at the ends of each panel. The depression of a given quadrant (quadrant $=1 / 2$ of each panel) closed the circuit on the microswitch, and each closing of a microswitch was counted as a single activity count. All animals were habituated to the chamber and to the injection procedure in a total of two sessions of 30 min each conducted 2 days before testing to decrease activational effects of the mild restraint used during the injection process and the novelty-activating effect of the chamber. On the day of testing, animals were placed in the chamber immediately after intracranial drug injections and locomotor behavior was recorded for $10 \mathrm{~min}$. In the sodium azide experiment (experiment 3c), animals were i.p. injected, placed back into their home cages for $30 \mathrm{~min}$, and then injected intracranially and placed in the activity chamber.

\section{Catalase Activity Determination}

Brain catalase activity was determined in independent groups of male rats ( $n=6$ per group). Rats were perfused using heparinized $(1000 \mathrm{U} / \mathrm{l})$ isotonic saline. The whole brain was removed and homogenized in a phosphate buffer (50 mmol/l; $\mathrm{pH} 7.0)$ with digitonin $(0.01 \%)$. Brain homogenates were centrifuged at 10000 r.p.m. $(8730 \mathrm{~g})$ for $10 \mathrm{~min}$ in an Eppendorf microcentrifuge. Supernatant aliquots were used to determine brain catalase levels. Catalase activity was assayed spectrophotometrically in the supernatants by measuring the decrease in absorbance of $\mathrm{H}_{2} \mathrm{O}_{2}$ at $240 \mathrm{~nm}$ $\left(\varepsilon_{240}=0.00394 \mathrm{mmol}^{-1} \times \mathrm{mm}^{-1}\right)($ Aebi, 1974). Protein levels were determined from supernatants (Bradford, 1976).

\section{Experiments}

Four experiments were conducted.

Experiment 1: SNr injections of ethanol. The first experiment assessed the effects of local injections of vehicle or ethanol $(0.175,0.35,0.7,1.4$, or $2.8 \mu \mathrm{mol})$ into the $\mathrm{SNr}$ on locomotor activity $(n=63)$. Based upon the results of this experiment, the $1.4 \mu \mathrm{mol}$ dose of ethanol was the highest dose used in experiment $2 \mathrm{a}$, and the only dose used in experiments $2 \mathrm{~b}$ and 3 .

Experiment 2: Ethanol injections into control sites. Experiment 2a studied the locomotor effects of injections of vehicle or ethanol $(0.35,0.7$, and $1.4 \mu \mathrm{mol})$ into a control site dorsal to the $\mathrm{SNr}(n=26)$. Experiment $2 \mathrm{~b}$ examined the effects of vehicle and $1.4 \mu \mathrm{mol}$ ethanol injected into a control site posterior to $\mathrm{SNr}(n=12)$.

Experiment 3: Effect of catalase inhibition on ethanolinduced activity. There were three components to this experiment. Experiment $3 \mathrm{a}$ was conducted to determine if $10 \mathrm{mg} / \mathrm{kg}$ of the catalase inhibitor sodium azide had any effect on locomotion when administered alone $(n=32)$. Animals received i.p. injections of either saline or $10 \mathrm{mg} / \mathrm{kg}$ sodium azide, and were tested for locomotion as described above. Experiment $3 \mathrm{~b}$ studied the effect of $10 \mathrm{mg} / \mathrm{kg}$ sodium azide on brain catalase activity $(n=12)$. Rats received i.p. injections of either saline or $10 \mathrm{mg} / \mathrm{kg}$ sodium azide, and were assessed for brain catalase activity as described above. Experiment $3 c$ employed a two-factor design to study the effect of catalase blockade on the locomotion induced by intranigral injections of ethanol $(n=37)$. Rats received an 
i.p. injection of either vehicle or $10 \mathrm{mg} / \mathrm{kg}$ of the catalase inhibitor sodium azide, and also received an injection of either vehicle or $1.4 \mu \mathrm{mol}$ ethanol directly into the SNr.

Experiment 4: SNr injections of acetaldehyde. The final experiment assessed the locomotor effects of local injections of vehicle or acetaldehyde $(0.35,0.7,1.4$, or $2.8 \mu \mathrm{mol})$ into the $\operatorname{SNr}(n=41)$.

\section{Histology}

After the experiments were completed, all animals were intracardially perfused with $0.9 \%$ saline. Brains were then stored refrigerated in $3.7 \%$ formaldehyde solution for at least 5 days prior to slicing. The placements of the injectors were verified histologically by collecting consecutive $50 \mu \mathrm{m}$ sections through the relevant brain areas. Sections were mounted on slides and stained with cresyl violet solution to aid in detection of the injector tracts. Coverslipped slides were viewed microscopically to assess accuracy of implantation. Any animal with improper placement in either hemisphere (ie, not in the target structures, such as $\mathrm{SNr}$ ), or significant damage around the injection site, was not included in the statistical analyses of behavioral data (22.7\% of all implantations were rejected). See Figure 1 for a photomicrograph of a representative $\mathrm{SNr}$ cannula and injector, showing placement in the $\mathrm{SNr}$ and negligible amounts of gliosis.

\section{Statistical Analysis}

Total locomotor activity data across the $10 \mathrm{~min}$ sessions were analyzed using one-way analysis of variance (ANOVA) in experiments $1,2 \mathrm{a}, 2 \mathrm{~b}$, and 4. Planned comparisons of differences between each drug dose and its respective vehicle control data were conducted using the LSD test. The chosen level of significance was set at $p \leqslant 0.05$. A $t$-test was used to analyze experiments $3 \mathrm{a}$ and $3 \mathrm{~b}$ because they involved only two groups. Experiment $3 c$ was analyzed using a $2 \times 2$ factorial ANOVA. These analyses were conducted using a computerized statistical program (Systat). For experiments 1 and 4, orthogonal analysis of trend was used to determine if the dose-response curves were characterized by linear or quadratic (ie, biphasic) functions (SPSS). A quadratic trend is one that displays a single bend

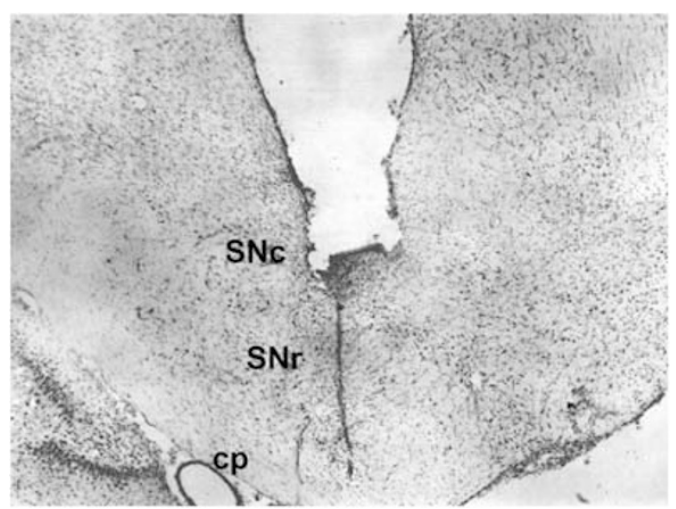

Figure I Photomicrograph of SNr with cannula and injector tracts. The animal received an injection of $2.8 \mu \mathrm{mol}$ of ethanol. SNc: substantia nigra pars compacta; SNr: substantia nigra pars reticulata; $\mathrm{cp}$ : cerebral peduncle either upward or downward; this is sometimes referred to as an inverted-U shape (Keppel, 1991).

\section{RESULTS}

\section{Experiment 1: SNr Injections of Ethanol}

A one-way ANOVA for the between factor dose of ethanol indicated that infusion of ethanol into the $\mathrm{SNr}$ led to a significant overall increase in locomotor activity $(\mathrm{F}(5,57)=3.52, \quad p<0.01) \quad($ see Figure 2). The planned comparisons revealed that all doses of ethanol except the lowest (ie, $0.175 \mu \mathrm{mol}$ ) produced increases in activity that were significantly different from the effects of vehicle $(1.4 \mu \mathrm{mol} p<0.01$; and $0.35,0.7$, and $2.8 \mu \mathrm{mol}, p<0.05)$. Trend analysis revealed that the overall dose-response curve showed a significant linear trend $(F(1,57)=5.0$, $p<0.05)$, and also showed a robust, statistically significant quadratic trend $(F(1,57)=10.3, p<0.005)$. None of the other trends were significant. The significant quadratic trend indicates that the dose-response curve for ethanol had an inverted-U shape, with a peak at $1.4 \mu \mathrm{mol}$. Figure 3 shows injector placements for animals that received the $1.4 \mu \mathrm{mol}$ dose of ethanol.

\section{Experiment 2: Ethanol Injections into Control Sites}

Ethanol $(0.0,0.35,0.7$, or $1.4 \mu \mathrm{mol})$ injected into the dorsal control site produced no significant change in behavior compared to the vehicle group, and there was also no effect of ethanol injections into the posterior control site (see Table 1; dorsal control: $\mathrm{F}(3,22)=0.486$, n.s.; posterior control: $\mathrm{F}(3,8)=0.53$, n.s.). Figures $4 \mathrm{a}$ and $\mathrm{b}$ show injector placements in the dorsal and posterior brainstem control sites, respectively.

\section{Experiment 3: Effect of Catalase Inhibition on Ethanol-Induced Activity}

Experiment 3a was conducted to determine if $10 \mathrm{mg} / \mathrm{kg}$ of the catalase inhibitor sodium azide had any effect on

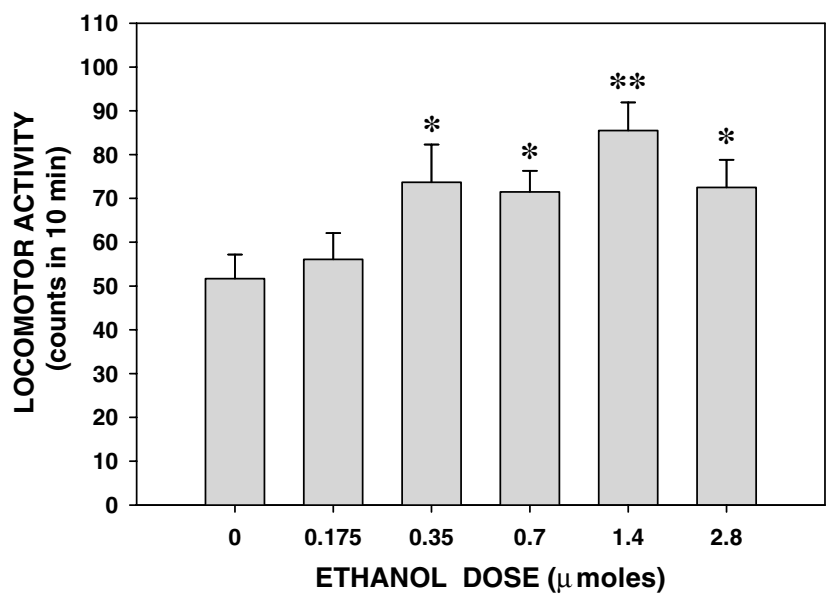

Figure 2 Effect of intranigral ethanol administration $(0.0,0.35,0.7,1.4$, or $2.8 \mu \mathrm{mol}$ ) on locomotor activity in rats. Mean \pm SEM represent counts in 10 min. ${ }^{*} * x<0.01, * p<0.05$ significantly different from vehicle. 


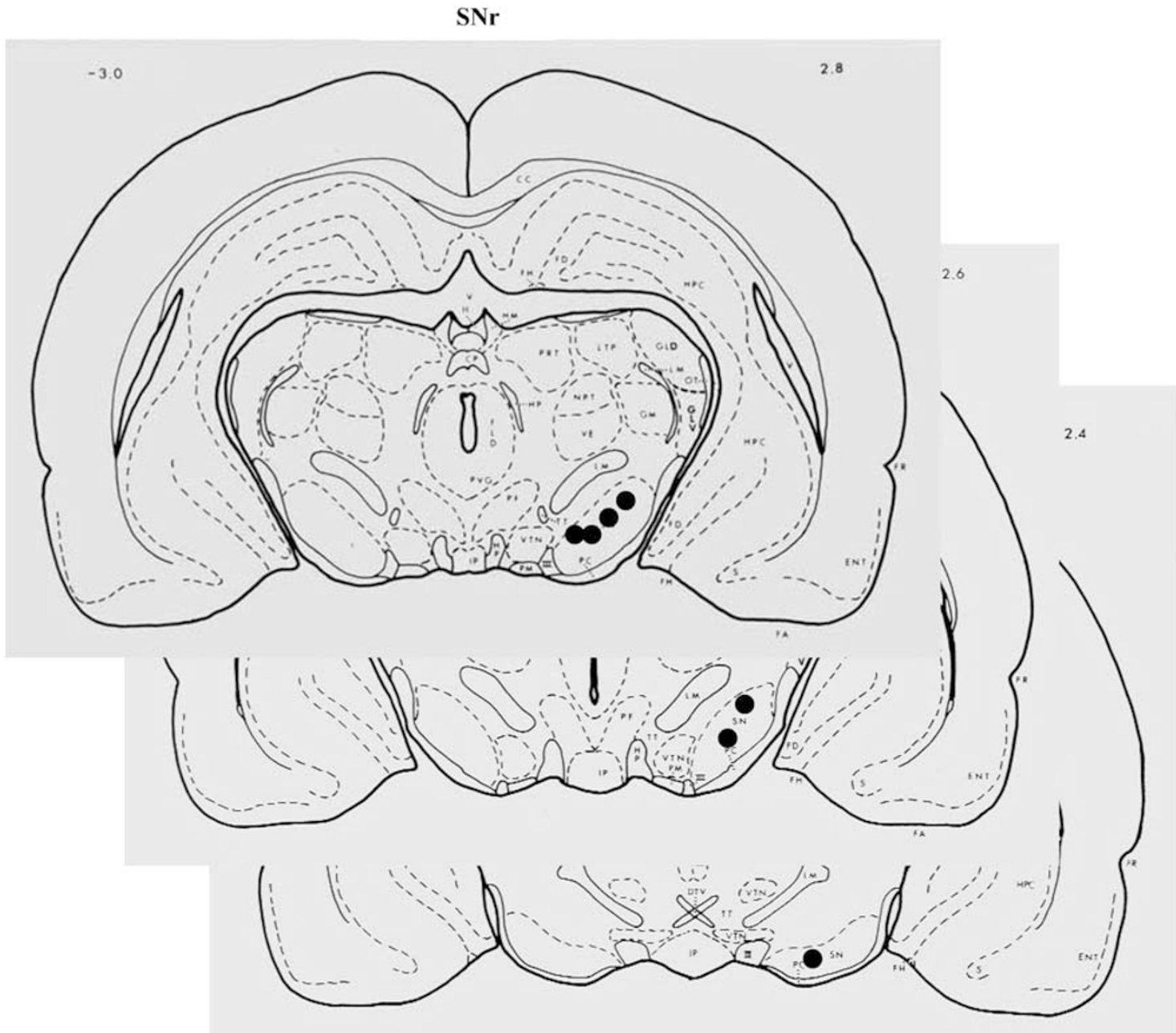

Figure 3 Cannula placements for animals that received the 1.4 $\mathrm{mol}$ dose of ethanol into SNr (right side only; Pellegrino and Cushman, 1967, plates 47-49) and the dorsal control site (left side only; Pellegrino and Cushman, 1967, plates 47 and 48).

Table I Effect of Ethanol Injection into Dorsal and Brainstem Control Sites on Locomotor Activity in Rats

\begin{tabular}{lllll}
\hline & \multicolumn{4}{c}{ Ethanol dose $(\boldsymbol{\mu m o l})$} \\
\cline { 2 - 5 } & Vehicle & $\mathbf{0 . 3 5}$ & $\mathbf{0 . 7}$ & $\mathbf{1 . 4}$ \\
\hline Dorsal control & $61.4 \pm 7.3$ & $56.6 \pm 8.7$ & $47.6 \pm 5.2$ & $55.3 \pm 6.9$ \\
Posterior control & $71.0 \pm 15.7$ & $84.0 \pm 10.0$ & $71.5 \pm 10.5$ & $60.3 \pm 12.6$
\end{tabular}

Mean \pm SEM represent counts in 10 min.

locomotion when administered alone. Mean ( \pm SEM) numbers of locomotor counts were as follows: saline vehicle, $46.7( \pm 4.6) ; 10 \mathrm{mg} / \mathrm{kg}$ sodium azide, $40.4( \pm 5.0)$. Statistical analysis showed no difference in locomotor activity between $10 \mathrm{mg} / \mathrm{kg}$ sodium azide and vehicle ( $t=0.94, \mathrm{df}=30$, n.s.). Experiment $3 \mathrm{~b}$ studied the effect of $10 \mathrm{mg} / \mathrm{kg}$ sodium azide on brain catalase activity. It was observed that $10 \mathrm{mg} / \mathrm{kg}$ sodium azide decreased brain catalase activity in rats by $40 \% 30 \mathrm{~min}$ after i.p. injection: vehicle $(n=6) 1.067 \pm 1.11 \mathrm{mmol} \mathrm{H}_{2} \mathrm{O}_{2} / \mathrm{min} / \mathrm{mg}$ protein; sodium azide $(n=6) \quad 0.636 \pm 0.44 \mathrm{mmol} \quad \mathrm{H}_{2} \mathrm{O}_{2} / \mathrm{min} / \mathrm{mg}$ protein $(t=3.58, \mathrm{df}=10, p<0.005)$.
Figure 5 shows the effect of i.p. administration of the catalase inhibitor sodium azide $(0$ or $10 \mathrm{mg} / \mathrm{kg}$ ) on the locomotion induced by intranigral ethanol $(0.0$ or $1.4 \mu \mathrm{mol})$. The two-way factorial ANOVA showed a significant overall effect of sodium azide treatment $(\mathrm{F}(1,33)=19.015, p<0.01)$, a significant effect of the ethanol factor $(\mathrm{F}(1,33)=12.282$, $p<0.01)$, and a significant sodium azide $\times$ ethanol interaction $(\mathrm{F}(1,33)=10.099, p<0.01)$, indicating that the effect of sodium azide on locomotion was different in animals treated with vehicle compared to those treated with ethanol. Post hoc comparisons with the Tukey test revealed that sodium azide alone did not suppress locomotion relative to the combined vehicle condition $(p<0.05)$. Administration of ethanol significantly increased locomotion compared to vehicle $(p<0.05)$, and sodium azide significantly reduced activity in ethanol-treated animals compared to ethanol alone $(p<0.05)$. Rats treated with ethanol alone also significantly differed from rats receiving sodium azide alone $(p<0.05)$.

\section{Experiment 4: SNr Injections of Acetaldehyde}

A one-way ANOVA with acetaldehyde dose as the main factor revealed that infusions of acetaldehyde directly into 
a

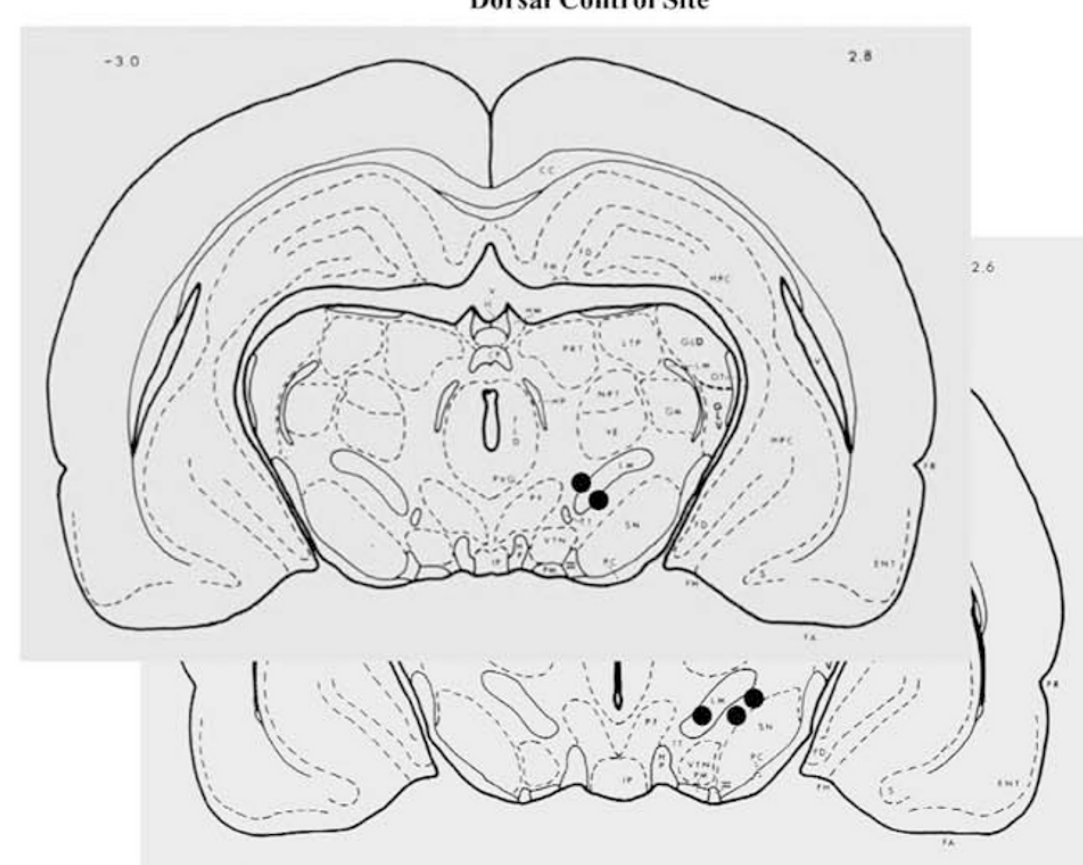

b

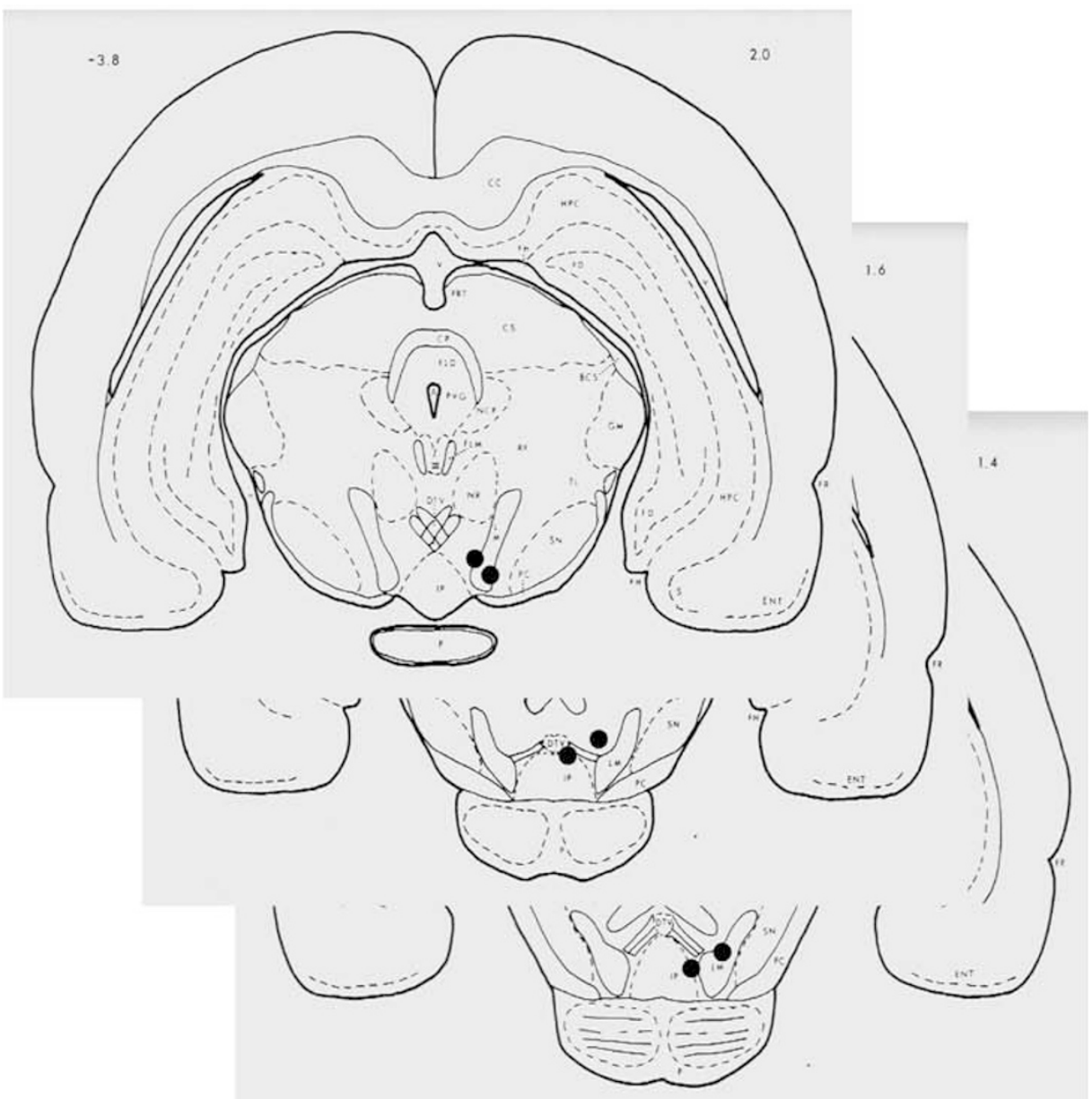

Figure 4 Placement of animals in the control site studies that received the $1.4 \mu \mathrm{mol}$ dose of ethanol into the brainstem control site (Pellegrino and Cushman, 1967, plates 5I, 53, and 54). 


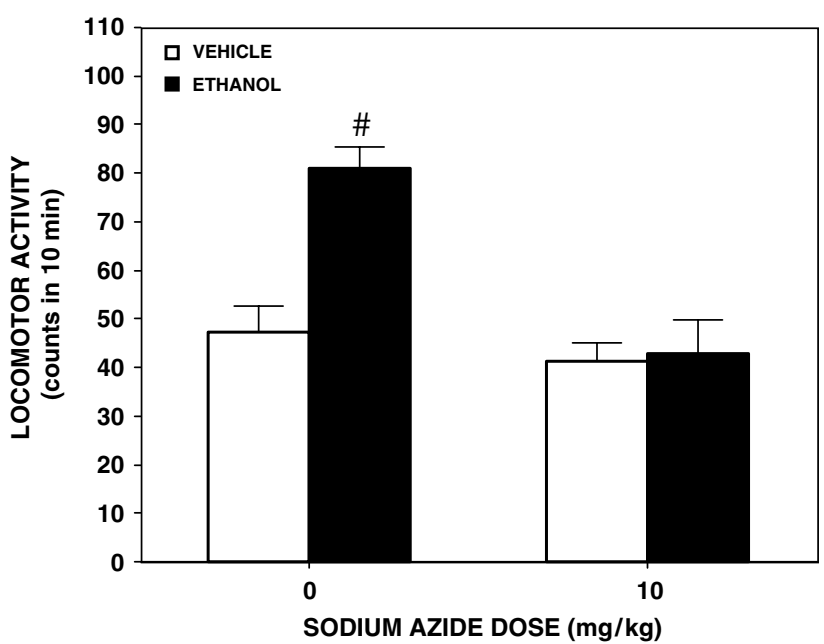

Figure 5 Effect of i.p. sodium azide injection $(0$ or $10 \mathrm{mg} / \mathrm{kg}, 30 \mathrm{~min}$ before test) on intranigral ethanol ( 0.0 or $1.4 \mu \mathrm{mol})$-induced locomotion in rats. Mean \pm SEM represent counts in 10 min. ${ }^{*} p<0.05$ significantly different from $0 \mathrm{mg} / \mathrm{kg}$ sodium azide-1.4 $\mu \mathrm{mol} ;{ }_{p} p<0.05$ significantly different from all other groups.

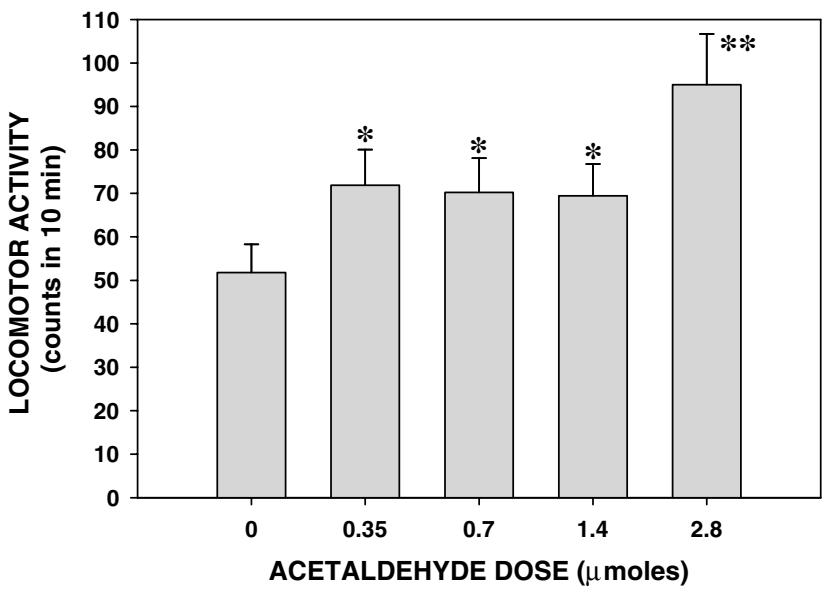

Figure 6 Effect of intranigral acetaldehyde administration (0.0, 0.35, 0.7, 1.4 , or $2.8 \mu \mathrm{mol}$ ) on locomotor activity in rats. Mean \pm SEM represent counts in 10 min. $* * * 0.01$, $* p<0.05$ significantly different from vehicle.

$\mathrm{SNr}$ produced a significant increase in locomotor activity $(\mathrm{F}(4,36)=3.36, p<0.05)$. The planned comparisons indicated that all doses significantly differed from vehicle $(2.8 \mu \mathrm{mol} p<0.01 ; 0.35,0.7$, and $1.4 \mu \mathrm{mol} p<0.05$; see Figure 6). The overall dose-response curve for acetaldehyde was characterized by a significant linear dose-related trend $(\mathrm{F}(1,36)=11.0, p<0.01)$, but not a significant quadratic trend $(\mathrm{F}(1,36)=0.05$, n.s. $)$.

\section{DISCUSSION}

\section{Summary of Results}

As described above, a series of experiments was conducted to investigate the locomotor effects of local injections of ethanol, and the ethanol metabolite acetaldehyde, into SNr. The first experiment demonstrated that infusions of ethanol into $\mathrm{SNr}$ resulted in a dose-related increase in locomotor activity. Additional experiments demonstrated that infusions of ethanol into control sites dorsal and posterior to $\mathrm{SNr}$ did not increase locomotion. The locomotor effects of intranigral ethanol were reduced by administration of sodium azide, a catalase inhibitor that acts to reduce ethanol metabolism. Moreover, $\mathrm{SNr}$ infusions of the ethanol metabolite acetaldehyde also increased locomotion. Taken together, these results indicate that $\mathrm{SNr}$ is one of the sites at which ethanol and acetaldehyde may be acting to induce locomotor activity. These experiments support the hypothesis that intracranial infusions of low doses of ethanol in rats can induce locomotion, and also provide further support for the hypothesis that metabolites of ethanol can be centrally active.

\section{Effects of SNr Infusions of Ethanol}

The first experiment demonstrated that infusions of ethanol directly into $\mathrm{SNr}$ resulted in a significant induction of locomotor activity. Although previous studies have employed intraventricular injection procedures, this is the first study reporting that locomotor activity can be induced by local infusions of ethanol into a discrete brain locus. With $\mathrm{SNr}$ infusions, the overall dose-response curve for the effect of ethanol tended to have an inverted-U shape, with $1.4 \mu \mathrm{mol}$ being the dose that produced the highest increase in locomotion. It is unlikely that these results occurred because of some general or nonspecific effect of infusion of ethanol somewhere into the brain, since additional experiments demonstrated that infusions of ethanol into control sites dorsal and posterior to SNr did not affect locomotion. In experiment 2, it was shown that injections of ethanol into a control site $2.6 \mathrm{~mm}$ dorsal to $\mathrm{SNr}$ failed to stimulate locomotor activity. In addition, placement sites in brainstem areas posterior to $\mathrm{SNr}$ also were shown to be inactive. Taken together, the results of these experiments indicate that $\mathrm{SNr}$ is a brain locus at which local infusions of ethanol can stimulate locomotor activity.

These studies have implications for understanding the brain mechanisms involved in mediating the ascending limb of the biphasic dose-response curve for the effect of ethanol on locomotor activity. The activating effects of systemic administration of ethanol have typically been shown in mice (Read et al, 1960; Frye and Breese, 1981; Crabbe et al, 1982; Masur et al, 1986; Aragon et al, 1992a; Phillips and Shen, 1996; Correa et al, 1999a, 2000, 2001, 2004b). Although some studies have shown that selectively bred alcohol-preferring rats can show ethanol-induced increases in locomotion (Paivarinta and Korpi, 1993; Colombo et al, 1998; Rodd et al, 2004), in most previous studies, peripheral administration of ethanol to other strains of rats failed to stimulate locomotor activity, and generally has resulted in a suppression of motor activity (Frye and Breese, 1981; Masur et al, 1986; Waller et al, 1986; Spivak et al, 1987; Aragon et al, 1989; Gingras and Cools, 1996; Correa et al, 2003a). More recently, through the use of intraventricular administration of ethanol directly into the brain, it has been demonstrated that central administration of ethanol in rats can induce locomotor activation (Correa et al, 2003a, b) and also increased operant responding on a DRL30 schedule, which is a sign of behavioral stimulant effects (Arizzi et al, 2003). These previous results are 
important, because they demonstrated that after an acute challenge of ethanol rats are capable of showing increased locomotor activity. However, these previous studies involving intraventricular administration did not assess the effects of local injections of ethanol directly into discrete brain areas. The current study demonstrated that ethanol can produce locomotor activation after infusion directly into the SNr.

With studies involving intracranial injections of drugs, there often are questions about the doses used, and the possibility of brain damage. The doses employed in the present study were at or below the doses that were used in recently published articles involving intraventricular administration (Arizzi et al, 2003; Correa et al, 2003a,b; Crankshaw et al, 2003), and were lower than those used in several earlier papers (Brown et al, 1978; Smith et al, 1984). Also, as described in detail by Correa et al (2003a, Selection of Intraventricular Doses, pp 369-370), the highest dose of intraventricular ethanol that was used in that study was 650-5200 times lower than a typical systemic dose in rats such as $1.0 \mathrm{~g} / \mathrm{kg}$ (eg, Quertemont et al, 2003). This ratio between intracranial and systemic doses of ethanol compares very favorably with the published literature involving intracranial injections of other drugs (Trevitt et al, 2001; Carlson et al, 2003b). For example, the obtained intracranial/systemic ratio for ethanol mentioned above is much lower than the intracranial/systemic ratio of the doses of the 5-HT 2 antagonist mianserin used in a recently published study (1 to 450 ratio; Carlson et al, 2003b). Thus, compared to other drugs that have been used both systemically and intracranially, the present doses of ethanol injected into the brain were generally lower when expressed as a fraction of the systemic dose range. Finally, it should be emphasized that in the present studies, as well as the previous papers involving intraventricular infusions (Arizzi et al, 2003; Correa et al, 2003a,b), none of the behavioral signs of administration of a high dose of ethanol (ie, ataxia, suppressed locomotion, suppressed lever pressing) were observed at any of the doses tested. Taken together, this evidence indicates that the doses of ethanol used in the present studies $(0.175-2.8 \mu \mathrm{mol})$ were not excessively high.

The possibility of brain damage induced by intracranial injections of ethanol or acetaldehyde also is important to address. In the Correa et al (2003a) article, a microscopic examination of intraventricular injection sites was conducted, and there was no significant difference in the severity of brain damage between animals that received 15 injections of $2.8 \mu \mathrm{mol}$ ethanol and those that received 15 injections of vehicle. In the present study, any animals that had signs of substantial damage in the vicinity of the injector relative to control rats were rejected from the study. Microscopic examination of the injection sites in the remaining animals indicated that the doses of ethanol used in the present study did not produce extensive damage (eg, Figure 1).

The specific neural mechanisms through which ethanol can induce locomotor activity are unknown, but several brain areas have been suggested to be involved in mediating the motor effects of ethanol, including the cerebellum (Dar, 2002), medial septal area (Givens and Breese, 1990), the central nucleus of the amygdala (Demarest et al, 1998), the arcuate nucleus of the hypothalamus (Sanchis-Segura et al, 2000, 2005), and basal ganglia (Dar, 2001). The present results demonstrate some degree of site specificity for the effects of $\mathrm{SNr}$ infusions of ethanol, because injections into control sites were ineffective. Nevertheless, it is not clear that $\mathrm{SNr}$ is the only active brain site for this effect. Preliminary data from our laboratory indicate that local injections of $1.4 \mu \mathrm{mol}$ ethanol into the posterior ventral tegmental area also can increase locomotor activity (Correa et al, 2005). Additional research will be necessary to map the ventral midbrain sites leading to ethanol-induced motor activity. In addition, the basic neurochemical effects of ethanol leading to the induction of locomotion also remain uncertain. Ethanol has been shown to interact with several neurotransmitter systems (Imperato and Di Chiara, 1986; Givens and Breese, 1990; Dar, 2001; Phillips and Shen, 1996; Ericson et al, 2003; Rodd-Henricks et al, 2003; Sanchis-Segura et al, 2004). Based upon the data reviewed above, it is possible that ethanol facilitates GABAA receptor function on $\mathrm{SNr}$ output neurons (Diana et al, 1993; Criswell et al, 1993, 1999). These neurons in turn project to various brainstem motor areas, including reticular formation and the pedunculopontine nucleus, which are thought to be involved in locomotion (Fallon and Laughlin, 1995). Thus, it is possible that local infusion of ethanol into $\mathrm{SNr}$ is stimulating locomotion through a mechanism that is similar to the one that is thought to be involved in muscimol-induced locomotion (Trevitt et al, 2002). However, further research is necessary to study this hypothesis.

\section{Role of Ethanol Metabolism}

Consistent with previous studies involving peripheral administration of ethanol in mice (Aragon et al, 1992a; Aragon and Amit, 1993; Correa et al, 1999a, b, 2000, 2001, 2004a, b; Sanchis-Segura et al, 1999a-c; Pastor et al, 2002), the present studies suggest that the metabolism of ethanol into acetaldehyde is involved in the locomotor stimulant effects of ethanol. In experiment 3, the locomotor effects of intranigral ethanol were blocked by peripheral administration of sodium azide, a catalase inhibitor that acts to reduce brain ethanol metabolism (Sanchis-Segura et al, 1999a; Correa et al, 2004b). The $10 \mathrm{mg} / \mathrm{kg}$ dose of sodium azide used in the present study reduced brain catalase activity by $40 \%$, but did not affect locomotion when administered on its own in two separate experiments. This is consistent with previous results indicating that sodium azide did not suppress the locomotion induced by $d$-amphetamine or tert-butanol (Sanchis-Segura et al, 1999a). These results suggest that catalase-induced metabolism of ethanol, and hence the production of acetaldehyde, is a plausible mechanism for some of the behavioral effects observed after ethanol administration. This statement is supported by the finding of increased locomotion after infusions of acetaldehyde into the $\mathrm{SNr}$ (experiment 4). Acetaldehyde infusions into the $\mathrm{SNr}$ in the same dose range as ethanol produced a monophasic induction of locomotion, with the maximum effect at $2.8 \mu \mathrm{mol}$ of acetaldehyde. The present findings are consistent with previous studies showing that intraventricular injections of acetaldehyde can induce locomotor activity (Correa et al, 2003b) and increase 
responding on a DRL30 operant schedule (Arizzi et al, 2003) over the same dose range as ethanol. It is not clear why acetaldehyde appears to have approximately the same potency as ethanol for inducing locomotion after intracranial injections. Based upon peripheral injection studies, one might think that acetaldehyde should be more potent than ethanol (eg, Quertemont et al, 2005b). However, the dose of intracranial acetaldehyde needed to induce locomotion could be influenced by many factors, and the rapid enzymatic elimination of acetaldehyde from the brain may be acting to reduce the apparent potency of this substance (Majchrowicz et al, 1967; Truitt and Walsh, 1971; Amit and Smith, 1985).

Although there is general acceptance of the concept that acetaldehyde is peripherally active as an ethanol metabolite (Holtzman and Schneider, 1974; Hillbom et al, 1983; Myers et al, 1984; Quertemont and Grant, 2002; Tampier and Quintanilla, 2002), there has been some controversy about the potential role of acetaldehyde in mediating some of the central effects of ethanol (Hunt, 1996). This controversy is due mainly to uncertainties about the presence of acetaldehyde in the brain after ethanol consumption, and the relatively low levels of this metabolite that have been detected (Hunt, 1996; Smith et al, 1997; Zimatkin and Deitrich, 1997). Nevertheless, increases in acetaldehydemetabolizing enzymes in the brain have been reported after previous ethanol exposure in rats, suggesting that acetaldehyde is present in the brain after consumption of ethanol (Amit et al, 1977; Amir, 1978). Moreover, recent studies have demonstrated the consistent detection of acetaldehyde in the brain after peripheral ethanol administration (Ward et al, 1997; Jamal et al, 2003). Some of the acetaldehyde present in the brain can be the result of acetaldehyde molecules that are produced peripherally and then reach the brain, although it is difficult for acetaldehyde to cross the blood-brain barrier because of the metabolic barrier presented by large concentrations of ALDH (Hunt, 1996; Quertemont and Tambour, 2004). Nevertheless, some acetaldehyde can be directly formed in the brain through the actions of catalase (Aragon et al, 1992b; Reddy et al, 1995; Zimatkin and Lindros, 1996; Hamby-Mason et al, 1997; Eysseric et al, 1997; Zimatkin et al, 1998). The notion that ethanol metabolism in the brain is important for some of the behavioral effects of ethanol is supported by the reports that manipulations of catalase activity exert a powerful effect on ethanol-induced behavior (Aragon et al, 1992a; Aragon and Amit, 1993; Correa et al, 1999a, b, 2000, 2001, 2004a,b; Sanchis-Segura et al, 1999a-c; Pastor et al, 2002). Additional support is provided by studies showing behavioral effects of acetaldehyde after central administration (Myers and Veale, 1969; Brown et al, 1978, 1979, 1980; Smith et al, 1984; Arizzi et al, 2003; Correa et al, 2003b, c; Rodd-Henricks et al, 2002; Rodd et al, 2005). The central administration of acetaldehyde avoids the issue of brain penetrability, and therefore more directly assesses the effects of central acetaldehyde on distinct aspects of behavior

According to the current model (eg, Aragon and Amit, 1985), because it is difficult for peripheral acetaldehyde to escape liver metabolism and to cross the blood-brain barrier (Sippel, 1974; Eriksson and Sippel, 1977; Quertemont and Tambour, 2004), it is more likely that ethanol escapes metabolism, crosses the blood-brain barrier, and is then converted into acetaldehyde in the brain via catalase (Cohen et al, 1980; Aragon and Amit, 1985; Aragon et al, $1992 b)$. With in vitro studies, it has been demonstrated that brain acetaldehyde concentration could be decreased by the administration of catalase inhibitors, but not by cytochrome $\mathrm{P}-450$ or $\mathrm{ADH}$ inhibitors, supporting the idea that the primary brain mechanism for the metabolism of ethanol into acetaldehyde after acute ethanol exposure is catalase (Aragon et al, 1992b). The present results, together with the published findings, indicate that ethanol-induced locomotion in rodents depends on brain catalase activity. In mice, there is a very high correlation across a broad range of conditions between brain catalase activity and the degree of locomotor response to systemic ethanol administration (Correa et al, 2001). The results of experiment 3 indicate that motor activity induced by $\mathrm{SNr}$ infusions of ethanol in rats also depends upon catalase activity.

\section{Conclusions}

Taken together, the results of the present experiments indicate that $\mathrm{SNr}$ is one of the brain sites at which ethanol and acetaldehyde may be acting to induce locomotor activity. Together with the data showing that acetaldehyde is a biologically active compound that stimulates locomotor activity, these results also indicate that the catalasemediated conversion of ethanol into acetaldehyde in the brain is an important biochemical step involved in the locomotor stimulation induced by low doses of ethanol. In view of the hypothesis that central acetaldehyde is partially mediating the activating effects of ethanol, it is important to examine the biochemical pathways and neural mechanisms that could be involved in these effects. In addition, it is critical to determine how acetaldehyde is exerting its basic cellular actions. Previous research on the effects of acetaldehyde on GABA-related mechanisms has yielded inconsistent results (Kuriyama et al, 1987; Hashimoto et al, 1989; Ward et al, 1997; Mascia et al, 2001). In a recent review (Quertemont et al, 2005b), it was noted that there is no clear evidence that acetaldehyde significantly interacts with glutamate or GABA transmission. Clearly, additional studies are needed to characterize the cellular mechanisms through which ethanol and acetaldehyde are acting to influence the function of neurons involved in the regulation of locomotion. Recent studies have shown that peripherally administered acetaldehyde can activate ventral tegmental neurons in a manner similar to ethanol (Foddai et al, 2004). In terms of future behavioral studies, it will be important to determine if the effects of ethanol or acetaldehyde injected into the $\mathrm{SNr}$ are blocked by administration of benzodiazepine antagonists or inverse agonists, in order to assess the role of the $\mathrm{GABA}_{\mathrm{A}}$ /benzodiazepine receptor complex in these effects.

\section{ACKNOWLEDGEMENTS}

We acknowledge Alicia Dosda and Cristina Figueiredo for technical assistance. This research was partially supported by a grant from Red de Trastornos Adictivos, Ministerio de Sanidad y Consumo (G03/005), Spain. 


\section{REFERENCES}

Abraini JH, Kriem B, Rostain JC (1999). Administration of the glutamate uptake inhibitor L-trans-PDC in the globus pallidus and the substantia nigra, but not in the striatum, attenuates the psychostimulant effect of high helium pressure on locomotor activity in the rat. Neurosci Res 35: 273-279.

Aebi H (1974). Catalase. In: Bergmeyer HV (ed). Methods of Enzymatic Analysis. Verlag Chemie: Basel. pp 673-684.

Amir S (1978). Brain aldehyde dehydrogenase: adaptive increase following prolonged ethanol administration in rats. Neuropharmacology 17: 463-467.

Amir S, Brown Z, Amit Z (1980). The role of acetaldehyde in the psychopharmacological effects of ethanol. In: Rigter HC, John C (eds). Alcohol Tolerance and Dependence. Elsevier/NorthHolland Biomedical Press: New York. pp 317-337.

Amit Z, Brown ZW, Rockman GE (1977). Possible involvement of acetaldehyde, norepinephrine, and their tetrahydroisoquinoline derivatives in the regulation of ethanol self-administration. Drug Alcohol Dependence 2: 495-500.

Amit Z, Smith BR (1985). A multi-dimensional examination of the positive reinforcing properties of acetaldehyde. Alcohol 2: 367-370.

Aragon CMG, Amit Z (1985). A two dimensional model of alcohol consumption: possible interaction of brain catalase and aldehyde dehydrogenase. Alcohol 2: 357-360.

Aragon CMG, Amit Z (1993). Differences in ethanol-induced behaviours in normal and acatalasemic mice: systematic examination using a biobehavioural approach. Pharmacol Biochem Behav 44: 547-554.

Aragon CMG, Pesold CN, Amit Z (1992a). Ethanol-induced motor activity in normal and acatalasemic mice. Alcohol 9: 207-211.

Aragon CMG, Rogan F, Amit Z (1992b). Ethanol metabolism in rat brain homogenates by the catalase $\mathrm{H}_{2} \mathrm{O}_{2}$ system. Biochem Pharmacol 44: 93-98.

Aragon CMG, Spivak K, Amit Z (1989). Effects of 3-amino-1,2,4triazole on ethanol-induced open field activity: evidence for brain catalase mediation of ethanol's effects. Alcohol Clin Exp Res 13: 104-108.

Aragon CMG, Stotland LM, Amit Z (1991). Studies on ethanolbrain catalase interaction: evidence for central ethanol oxidation. Alcohol Clin Exp Res 15: 165-169.

Arizzi MN, Correa M, Betz A, Wisniecki A, Salamone JD (2003). Behavioral effects of intraventricular injections of low doses of ethanol, acetaldehyde, and acetate in rats: studies with low and high rate operant schedules. Behav Brain Res 147: 203-210.

Bevan MD, Smith AD, Bolam JP (1996). The substanita nigra as a site of synaptic integration of functionally diverse information arising from the ventral pallidum and the globus pallidus in the rat. Neurosci Lett 75: 5-12.

Bradford MM (1976). A rapid and sensitive method for the quantification of microgram quantities of protein utilizing the principle of protein-dye binding. Anal Biochem 72: 248-254.

Brannan TS, Maker HS, Raes IP (1981). Regional distribution of catalase in the adult rat brain. J Neurochem 36: 307-309.

Brown ZW, Amit Z, Rockman GE (1979). Intraventricular selfadministration of acetaldehyde, but not ethanol, in naive laboratory rats. Psychopharmacology 64: 271-276.

Brown ZW, Amit Z, Smith B (1980). Intraventricular selfadministration of acetaldehyde and voluntary consumption of ethanol in rats. Behav Neural Biol 28: 150-155.

Brown ZW, Amit Z, Smith B, Rockman GE (1978). Differential effects on conditioned taste aversion learning with peripherally and centrally administered acetaldehyde. Neuropharmacology 17: 931-935.

Carlson BB, Behrstock S, Tobin AJ, Salamone JD. (2003a). Brain implantations of engineered GABA-releasing cells suppress tremor in an animal model of Parkinsonism. Neuroscience 119: 927-932.
Carlson BB, Wisniecki A, Salamone JD (2003b). Local injections of the 5-hydroxytryptamine antagonist mianserin into substantia nigra pars reticulata block tremulous jaw movements in rats: studies with a putative model of Parkinsonian tremor. Psychopharmacology 165: 229-237.

Cohen G, Sinet PM, Heikkila R (1980). Ethanol oxidation by rat brain in vivo. Alcohol Clin Exp Res 4: 366-370.

Colombo G, Agabio R, Lobina C, Reali R, Vacca G, Gessa GL (1998). Stimulation of locomotor activity by voluntarily consumed ethanol in Sardinian alcohol-preferring rats. Eur $J$ Pharmacol 357: 109-113.

Correa M, Arizzi MN, Betz A, Mingote S, Salamone JD (2003a). Locomotor stimulant effects of intraventricular injections of ethanol in rats: acute and repeated administration. Psychopharmacology 170: 368-375.

Correa M, Arizzi MN, Betz A, Mingote S, Salamone JD (2003b). Open field locomotor effects in rats after intraventricular injections of ethanol and the ethanol metabolites acetaldehyde and acetate. Brain Res Bull 62: 197-202.

Correa M, Arizzi MN, Salamone JD (2005). Behavioral stimulant effects of intracranial injections of ethanol and acetaldehyde in rats. In: The role of acetaldehyde in the central effects of ethanol (Quertemont E, Grant KA, Correa M, Arizzi MN, Salamone JD, Tambour S, Aragon CMG, McBride WJ, Rodd ZA, Goldstein A, Zaffaroni A, Li TK, Pisano M, Diana M.). Alcohol Clin Exp Res 29: 221-224.

Correa M, Mingote S, Betz A, Wisniecki A, Salamone JD (2003c). Substantia nigra pars reticulata GABA is involved in the regulation of operant lever pressing: pharmacological and microdialysis studies. Neuroscience 119: 759-766.

Correa M, Miquel M, Aragon CMG (2000). Lead acetate potentiates brain catalase activity and enhances ethanol-induced locomotion in mice. Pharmacol Biochem Behav 66: 137-142.

Correa M, Miquel M, Sanchis-Segura C, Aragon CMG (1999a). Acute lead acetate administration potentiates ethanol-induced locomotor activity in mice: the role of brain catalase activity. Alcohol Clin Exp Res 23: 799-805.

Correa M, Miquel M, Sanchis-Segura C, Aragon CMG (1999b). Effects of chronic lead administration on ethanol-induced locomotor and brain catalase activity. Alcohol 19: 43-49.

Correa M, Roig-Navarro AF, Aragon CMG (2004a). Motor behavior and brain enzymatic changes after acute lead intoxication on different strains of mice. Life Sci 74: 2009-2021.

Correa M, Sanchis-Segura C, Aragon CMG (2001). Brain catalase activity is highly correlated with ethanol-induced locomotor activity in mice. Physiol Behav 73: 641-647.

Correa M, Sanchis-Segura C, Pastor R, Aragon CMG (2004b). Ethanol intake and motor sensitization: the role of brain catalase activity in mice with different genotypes. Physiol Behav 82: 231-240.

Crabbe JC, Johnson NA, Gray DK, Kosobud A, Young ER (1982). Biphasic effects of ethanol on open field activity: sensitivity and tolerance to $\mathrm{C} 57 \mathrm{BL} / 6 \mathrm{~N}$ and $\mathrm{DBA} / 2 \mathrm{~N}$ mice. J Comp Physiol Psychol 96: 440-451.

Crankshaw DL, Briggs JE, Olszewski PK, Shi Q, Grace MK, Billington CJ et al (2003). Effects of intracerebroventricular ethanol on ingestive behavior and induction of c-Fos immunoreactivity in selected brain regions. Physiol Behav 79: 113-120.

Criswell HE, McCown TJ, Ming Z, Mueller RA, Breese GR (1999). Interactive role for neurosteroids in ethanol enhancement of $\gamma$ aminobutyric acid-gated currents from dissociated substantia nigra reticulata neurons. J Pharmacol Exp Ther 291: 1054-1059.

Criswell HE, Simson PE, Duncan GE, McCown TJ, Herbert JS, Morrow AL et al (1993). Molecular basis for regionally specific action of ethanol on gamma-aminobutyric acid A receptors: generalization to other ligand-gated ion channels. J Pharmacol Exp Ther 267: 522-537. 
Crocker AD (1997). The regulation of motor control: an evaluation of the role of dopamine receptors in the substantia nigra. Rev Neurosci 8: 55-76.

Dar MS (2001). Modulation of ethanol-induced motor incoordination by mouse striatal A(1) adenosinergic receptor. Brain Res Bull 55: 513-520.

Dar MS (2002). Mouse cerebellar adenosine-glutamate interactions and modulation of ethanol-induced motor incoordination. Alcohol Clin Exp Res 26: 1395-1403.

Demarest K, Hitzemann B, Mahjubi E, McCaughran J, Hitzemann R (1998). Further evidence that the central nucleus of the amygdala is associated with the ethanol-induced locomotor response. Alcohol Clin Exp Res 22: 1531-1537.

Diana M, Pistis M, Muntoni A, Gessa G (1993). Heterogeneous responses of substantia nigra pars reticulata neurons to gammahydroxybutyric acid administration. Eur J Pharmacol 230: 363-365.

Dudek BC, Phillips TJ (1990). Distinctions among sedative, disinhibitory and ataxic properties of ethanol in inbred and selectively bred mice. Pychopharmacology 101: 93-99.

Ericson M, Molander A, Lof E, Engel JA, Soderpalm B (2003). Ethanol elevates accumbal dopamine levels via indirect activation of ventral tegmental nicotinic acetylcholine receptors. Eur J Pharmacol 467: 85-93.

Eriksson CJP, Sippel HW (1977). The distribution and metabolism of acetaldehyde in rats during ethanol oxidation-I. The distribution of acetaldehyde in liver, brain, blood, and breath. Biochem Pharmacol 26: 241-247.

Eysseric H, Gonthier B, Soubeyran A, Bessard G, Saxod R, Barret L (1997). Characterization of the production of acetaldehyde by astrocytes in culture after ethanol exposure. Alcohol Clin Exp Res 21: 1018-1022.

Fallon JH, Laughlin SE (1995). Substantia nigra. In: Paxinos G (ed). The Rat Nervous System. Academic Press: San Diego. pp 215237.

Finn M, Mayorga AJ, Salamone JD (1997). Involvement of pallidal and nigral GABA mechanisms in the generation of tremulous jaw movements in rats. Neuroscience 80: 535-544.

Foddai M, Dosia G, Spiga S, Diana M. (2004). Acetaldehyde increases dopaminergic neuronal activity in the VTA. Neuropsychopharmacology 29: 530-536.

Frye GD, Breese GR (1981). An evaluation of the locomotor stimulating action of ethanol in rats and mice. Psychopharmacology 75: 372-379.

Gill K, Menez JF, Lucas D, Deitrich RA (1992). Enzymatic production of acetaldehyde from ethanol in rat brain tissue. Alcohol Clin Exp Res 16: 910-915.

Gingras MA, Cools AR (1996). Analysis of the biphasic locomotor response to ethanol in high and low responders to novelty: a study in Nijmegen Wistar rats. Psychopharmacology 125: 258-264.

Givens B, Breese GR (1990). Site-specific enhancement of gammaaminobutyric acid-mediated inhibition of neural activity by ethanol in the rat medial septum. J Pharmacol Exp Ther 254: 528-538.

Gonzalez LP, Czachura JF (1989). Reduced behavioral responses to intranigral muscimol following chronic ethanol. Physiol Behav 46: 473-477.

Grant KA, Lovinger DM (1995). Cellular and behavioral neurobiology of alcohol: receptor-mediated neuronal processes. Clin Neurosci 3: 155-164.

Grobin AC, Matthews DB, Devaud LL, Morrow AL (1998). The role of $\mathrm{GABA}_{\mathrm{A}}$ receptors in the acute and chronic effects of ethanol. Psychopharmacology 139: 2-19.

Hamby-Mason R, Chen JJ, Schenker S, Perez A, Henderson GI (1997). Catalase mediates acetaldehyde formation from ethanol in fetal and neonatal rat brain. Alcohol Clin Exp Res 21: 1063-1072.
Hashimoto T, Ueha T, Kuriyama T, Katsura M, Kuriyama K (1989). Acetaldehyde-induced alterations in metabolism of monoamines in mouse brain. Alcohol Alcoholism 24: 91-99.

Hillbom ME, Sarviharju MS, Lindros KO (1983). Potentiation of ethanol toxicity by cyanamide in relation to acetaldehyde accumulation. Toxicol Appl Pharmacol 70: 133-139.

Holtzman SG, Schneider FH (1974). Comparison of acetaldehyde and ethanol: depression of motor activity in mice. Life Sci 14: 1243-1250.

Hunt WA (1996). Role of acetaldehyde in the actions of ethanol on the brain: a review. Alcohol 13: 147-151.

Imperato A, Di Chiara G (1986). Preferential stimulation of dopamine release in the nucleus accumbens of freely moving rats by ethanol. J Pharmacol Exp Ther 239: 219-228.

Jamal M, Ameno K, Kumihashi M, Ameno S, Kubota T, Wang W et al (2003). Microdialysis for the determination of acetaldehyde and ethanol concentrations in the striatum of freely moving rats. J Chromatogr B 798: 155-158.

Keppel G (1991). Design and Analysis: A Researcher's Handbook. Prentice-Hall: Englewood Cliffs, NJ.

Kuriyama K, Ohkuma S, Tomono S, Hirouchi M. (1987). Effects of alcohol and acetaldehyde on metabolism and function of neurotransmitter systems in cerebral cortical neurons in primary culture. Alcohol Alcoholism Suppl 1: 685-689.

Little HJ (2000). Alcohol as a stimulant drug. Addiction 95: 1751-1753.

Majchrowicz E, Bercaw BL, Cole WM, Gregory DH (1967). Nicotinamide adenine dinucleotide and the metabolism of ethanol and acetaldehyde. Q J Stud Alcohol 28: 213-224.

Marrosu F, Carcangiu G, Passino N, Aramo S, Mereu G (1989). Antagonism of ethanol effects by Ro 15-4513: an electrophysiological analysis. Synapse 3: 117-128.

Mascia MP, Maiya R, Borghese CM, Lobo IA, Hara K, Yamakura T et al (2001). Does acetaldehyde mediate ethanol action in the central nervous system? Alcohol Clin Exp Res 25: 1570-1575.

Masur J, Oliveira de Souza ML, Zwicker AP (1986). The excitatory effects of ethanol: absence in rats, no tolerance and increased sensitivity in mice. Pharmacol Biochem Behav 24: $1125-1128$.

Mayorga AJ, Trevitt JT, Conlan A, Gianutsos G, Salamone JD (1999). Striatal and nigral mechanisms involved in the antiparkinsonian effects of SKF 82958 (APB): studies of tremulous jaw movements in rats. Psychopharmacology 143: $72-81$.

McKenna O, Arnold G, Holtzman E (1976). Microperoxisome distribution in the central nervous system of the rat. Brain Res 117: 181-194.

Mereu G, Gessa GL (1985). Low doses of ethanol inhibit the firing of neurons in the substantia nigra, pars reticulata: a GABAergic effect? Brain Res 360: 325-330.

Moreno S, Mugnaini E, Ceru MP (1995). Immunocytochemical localization of catalase in the central nervous system of the rat. J Histochem Cytochem 43: 1253-1267.

Myers RD, Veale WL (1969). Alterations in volitional alcohol intake produced in rats by chronic intraventricular infusions of acetaldehyde, paraldehyde or methanol. Arch Int Pharmacodyn Ther 180: 100-113.

Myers WD, Ng KT, Singer G (1984). Effects of naloxone and buprenorphine on intravenous acetaldehyde self-injection in rats. Physiol Behav 33: 449-455.

Nurmi M, Kiianmaa K, Sinclair JD. (1999). Brain ethanol levels after voluntary ethanol drinking in AA and Wistar rats. Alcohol 19: 113-118.

Paivarinta P, Korpi ER. (1993). Voluntary ethanol drinking increases locomotor activity in alcohol-preferring AA rats. Pharmacol Biochem Behav 44: 127-132.

Pastor R, Sanchis-Segura C, Aragon CMG (2002). Ethanolstimulated behaviour in mice is modulated by brain catalase 
activity and $\mathrm{H}_{2} \mathrm{O}_{2}$ rate of production. Psychopharmacology 165: 51-59.

Pellegrino LJ, Cushman AJ (1967). A Stereotaxic Atlas of the Rat Brain. Appleton Century Crofts: New York.

Phillips TJ, Shen EH (1996). Neurochemical bases of locomotion and ethanol stimulant effects. Int Rev Neurobiol 39: 243-282.

Phillips TJ, Shen EH, McKinnon CS, Burkhart-Kasch S, Lessov CN, Palmer AA (2002). Forward, relaxed, and reverse selection for reduced and enhanced sensitivity to ethanol's locomotor stimulant effects in mice. Alcohol Clin Exp Res 26: 593-602.

Pohorecky LA (1977). Biphasic action of ethanol. Biobehav Rev 1: 231-240.

Quertemont E, Grant KA (2002). Role of acetaldehyde in the discriminative stimulus effects of ethanol. Alcohol Clin Exp Res 26: 812-817.

Quertemont E, Grant KA, Correa M, Arizzi MN, Salamone JD, Tambour S et al (2005a). The role of acetaldehyde in the central effects of ethanol. Alcohol Clin Exp Res 29: 221-234.

Quertemont E, Green HL, Grant KA (2003). Brain ethanol concentrations and ethanol discrimination in rats: effects of dose and time. Psychopharmacology 168: 262-270.

Quertemont E, Tambour S (2004). Is ethanol a pro-drug? Role of acetaldehyde in the central effects of ethanol. Trends Pharmacol Sci 25: 130-134.

Quertemont E, Tambour S, Tirelli E. (2005b). The role of acetaldehyde in the neurobehavioral effects of ethanol: a comprehensive review of animal studies. Prog Neurobiol 75: 247-274.

Read GW, Cutting W, Furst A (1960). Comparison of excited phases after sedatives and tranquilizers. Psychopharmacologia 1: 346-350.

Reddy BV, Boyadjieva N, Sarkar DK (1995). Effect of ethanol, propanol, butanol, and catalase enzyme blockers on betaendorphin secretion from primary cultures of hypothalamic neurons: evidence for a mediatory role of acetaldehyde in ethanol stimulation of beta-endorphin release. Alcohol Clin Exp Res 19: 339-344.

Rodd ZA, Bell RL, McKinzie DL, Webster AA, Murphy JM, Lumeng $\mathrm{L}$ et al (2004). Low-dose stimulatory effects of ethanol during adolescence in rat lines selectively bred for high alcohol intake. Alcohol Clin Exp Res 28: 535-543.

Rodd ZA, Bell RL, Zhang Y, Murphy JM, Goldstein A, Zaffaroni A et al (2005). Regional heterogeneity for the intracranial selfadministration of ethanol and acetaldehyde within the ventral tegmental area of alcohol-preferring $(\mathrm{P})$ rats: involvement of dopamine and serotonin. Neuropsychopharmacology 30: 330-338.

Rodd-Henricks ZA, McKinzie DL, Melendez RI, Berry N, Murphy JM, McBride WJ (2003). The effects of serotonin-3 receptor antagonists on the intracranial self-administration of ethanol into the posterior VTA of Wistar rats. Psychopharmacology 165: 252-259.

Rodd-Henricks ZA, Melendez RI, Zaffaroni A, Goldstein A, McBride WJ, Li T-K (2002). The reinforcing effects of acetaldehyde in the posterior ventral tegmental area of alcohol-preferring rats. Pharmacol Biochem Behav 72: 55-64.

Sanchis-Segura C, Correa M, Aragon CMG (2000). Lesion on the hypothalamic arcuate nucleus by estradiol valerate results in a blockade of ethanol-induced locomotion. Behav Brain Res 114: 57-63.

Sanchis-Segura C, Correa M, Miquel M, Aragon CMG (2005). Catalase inhibition in the arcuate nucleus blocks ethanol effects on locomotion in rats. Neurosci Lett 376: 66-70.

Sanchis-Segura C, Miquel M, Correa M, Aragon CMG (1999a). The catalase inhibitor sodium azide reduces ethanol-induced locomotor activity. Alcohol 19: 37-42.

Sanchis-Segura C, Miquel M, Correa M, Aragon CMG (1999b). Cyanamide reduces brain catalase and etanol-induced locomotor activity: is there a functional link? Psychopharmacology 144: 83-89.

Sanchis-Segura C, Miquel M, Correa M, Aragon CMG (1999c). Daily injections of cyanamide enhance both ethanol-induced locomotion and brain catalase activity. Behav Pharmacol 10: 459-465.

Sanchis-Segura C, Pastor R, Aragon CMG (2004). Opposite effects of acute versus chronic naltrexone administration on ethanolinduced locomotion. Behav Brain Res 153: 61-67.

Scheel-Kruger J, Arnt J, Magelund G (1977). Behavioural stimulation induced by muscimol and other GABA antagonists injected into the substantia nigra. Neurosci Lett 4: 351-356.

Scheel-Kruger J, Magelund G, Olianas MC (1981). Role of GABA in the striatal output system: globus pallidus, nucleus entopeduncularis, substantia nigra, and nucleus subthalamicus. $A d v$ Biochem Psychopharmacol 30: 165-186.

Sippel HW (1974). The acetaldehyde content in rat brain during ethanol metabolism. J Neurochem 23: 451-452.

Smith BR, Amit Z, Splawinsky J (1984). Conditioned place preference induced by intraventricular infusions of acetaldehyde. Alcohol 1: 193-195.

Smith BR, Aragon CM, Amit Z (1997). Catalase and the production of brain acetaldehyde: a possible mediator for the psychopharmacological effects of ethanol. Addict Biol 2: 277-289.

Spivak K, Aragon CMG, Amit Z (1987). Alterations in brain aldehyde dehydrogenase activity modify the locomotor effects produced by ethanol in rats. Alcohol Drug Res 7: 481-491.

Tampier L, Quintanilla ME (2002). Effect of acetaldehyde on acute tolerance and ethanol consumption in drinker and nondrinker rats. J Stud Alcohol 63: 257-262.

Trevitt JT, Carlson BB, Correa M, Keene A, Morales M, Salamone JD (2002). Interactions between dopamine D1 receptors and g-aminobutyric acid mechanisms in substantia nigra pars reticulata of the rat: neurochemical and behavioral studies. Psychopharmacology 159: 229-237.

Trevitt JT, Carlson BB, Nowend K, Salamone JD (2001). Substantia nigra pars reticulata is a highly potent site of action for the behavioral effects of SCH 23390. Psychopharmacology 156: $32-41$.

Truitt EB, Walsh EB (1971). The role of acetaldehyde in the actions of ethanol. In: Kissin $\mathrm{B}$, Begeliter $\mathrm{H}$ (eds). The Biology of Alcoholism. Plenum Press: New York. Vol 1, pp 161-195.

Waller MB, Murphy JM, McBride WJ, Lumeng L, Li TK (1986). Effect of low dose ethanol on spontaneous motor activity in alcohol-preferring and non-preferring lines of rats. Pharmacol Biochem Behav 24: 617-623.

Ward RJ, Colantuoni C, Dahcuour A, Quertemont E, de White P (1997). Acetaldehyde-induced changes in the monoamine and amino acid extracellular microdialysate content of the nucleus accumbens. Neuropharmacology 36: 225-232.

Wichmann T, Bergmann H, Starr PA, Subramanian T, Watts RL, Delong MR (1999). Comparison of MPTP-induced changes in spontaneous neuronal discharge in the internal pallidal segment and in the substantia nigra pars reticulata in primates. Exp Brain Res 125: 397-409.

Young AB, Penney JB (1993). Biochemical and functional organization of the basal ganglia. In: Jankonvic J, Tolosa E (eds). Parkinson's Disease and Movement Disorders. Williams and Wilkins: Baltimore. pp 1-12.

Zimatkin SM, Deitrich RA (1997). Ethanol metabolism in the brain. Addict Biol 2: 387-399.

Zimatkin SM, Lindros KO (1996). Distribution of catalase in rat brain: aminergic neurons as possible targets for ethanol effects. Alcohol Alcoholism 31: 167-174.

Zimatkin SM, Liopo AV, Deitrich RA (1998). Distribution and kinetics of ethanol metabolism in rat brain. Alcohol Clin Exp Res 22: $1623-1627$. 